\section{Psychometric properties of the Brazilian version of the Vulnerable Elders Survey-13 (VES-13)}

\author{
Propriedades psicométricas da versão brasileira do \\ instrumento Vulnerable Elders Survey-13 (VES-13)
}

\section{Propiedades psicométricas de la versión brasileña del instrumento Vulnerable Elders Survey-13} (VES-13)

\title{
$(\mathrm{VES}-13)$
}

\author{
${ }^{1}$ Escola Nacional de Saúde \\ Pública Sergio Arouca, \\ Fundação Oswaldo Cruz, \\ Rio de Janeiro, Brasil. \\ 2 Faculdade de Medicina, \\ Universidade Federal do \\ Rio de Janeiro, Rio de Janeiro, \\ Brasil. \\ 3 Faculdade de Medicina, \\ Universidade Federal do \\ Mato Grosso do Sul, \\ Campo Grande, Brasil. \\ Correspondence \\ L. L. Luz \\ Escola Nacional de Saúde \\ Pública Sergio Arouca, \\ Fundação Oswaldo Cruz. \\ Rua Leopoldo Bulhões 1480, \\ Rio de Janeiro, $R J$ \\ 21041-210, Brasil \\ laercioll@hotmail.com
}

\begin{abstract}
This study aims to assess the psychometric properties of the Brazilian version of the Vulnerable Elders Survey-13 (VES-13). Interviews were carried out with individuals aged 60 years and over receiving care at an ambulatory cancer centre. Test-retest reliability was assessed using the Spearman correlation coefficient, intraclass correlation coefficients and Cohen's kappa coefficient. Construct validity was assessed by testing convergent and discriminant validity using principal component analysis and Varimax rotation. The Spearman correlation coefficient value of the comparison between test and retest scores was $0.98(p<0.001)$. All intraclass correlation coefficient values were higher than 0.60 and kappa coefficients varied between 0.33 and 0.94. Three identified factors explained $72.6 \%$ of overall sample variance. VES-13 presented good convergent validity and reasonable discriminant validity. The psychometric properties of the adapted version of the VES-13 are consistent and adequate for use with the Brazilian population.
\end{abstract}

Aged; Psychometrics; Vulnerable Groups
Laércio Lima Luz 1

Lívia Maria Santiago 1,2

João Francisco Santos da Silva 3

Inês Echenique Mattos ${ }^{1}$

\section{Resumo}

Este estudo visa a avaliar as propriedades psicométricas da versão brasileira do Vulnerable Elders Survey-13 (VES-13). Entrevistas com indivíduos de 60 anos ou mais, atendidos em unidade ambulatorial de hospital de câncer. Confiabilidade testereteste avaliada com coeficiente de correlação de Spearman, coeficientes de correlação intraclasse e kappa. Análise exploratória para avaliação do constructo por meio da análise de componentes principais com rotação varimax. Validade de constructo examinada por validade convergente e divergente. O coeficiente de correlação de Spearman entre os escores de teste e reteste foi 0,98 ( $p<0,001)$. Todos os coeficientes de correlação intraclasse apresentaram valores maiores que 0,60 e os coeficientes kappa variaram entre 0,33 e 0,94. Três fatores explicaram $72,6 \%$ da variância total da amostra. O VES-13 apresentou boa validade convergente e validade divergente razoável. A versão brasileira do VES-13 apresentou propriedades psicométricas consistentes.

Idoso; Psicometria; Comunidades Vulneráveis 


\section{Introduction}

The Vulnerable Elders Survey-13 (VES-13) is a tool developed in the United States for screening individuals aged 65 and older living in the community and Medicare users 1 . The purpose of the tool is to identify elderly people with an increased risk of death or functional decline: the so-called vulnerable elders 1 . The tool considers 13 items covering age, self-rated health, functional capacity and physical condition. Using the VES-13 and adopting a score greater than or equal to three as a vulnerability cutpoint, the authors detected vulnerability in $32 \%$ of older people and observed that the risk of death or functional decline was four times greater in this group than in groups with a score of less than three 1 .

A study involving prostate cancer patients conducted in Chicago (United States) assessed the psychometric properties of the VES-13 2 . Test-retest reliability was assessed using Pearson's correlation coefficient (r) and criterion validity was tested by comparing VES-13 results with those obtained using a standardized Comprehensive Geriatric Assessment (CGA), which is considered the gold standard. With respect to reliability, the analysis showed a strong correlation $(r=0.92)$ between the results of the first questionnaire and those of a new questionnaire conducted 30 days later. Separate analyses were undertaken of self-rated health $(r=0.52)$, physical capacity $(\mathrm{r}=0.60)$ and functional capacity (0.70). With regard to the validity of the VES-13, sensitivity and specificity was $72.7 \%$ and $85.7 \%$, respectively, while the positive predictive value was $88.9 \%$, in comparison to the gold standard (CGA) which had an area under the curve (AUC) of 0.90 (95\%CI: $0.80-0.99$ ). The tool also proved to be a good predictor of changes in activities of daily living (ADL) and instrumental activities of daily living (IADL), and of comorbidities 2 .

The VES-13 has been used in the United States and Europe to assess elderly patients with different types of cancer 3,4,5,6. On the whole, the results of these studies confirm the validity and feasibility of using the VES-13 as a tool for identifying vulnerable older people with cancer. However, no studies were found that assessed the construct validity of the VES-13.

In light of the above, we decided to create a cross-cultural adaption of the VES-13 for use with the Brazilian population targeting older people with cancer. In the first stage of the process, an analysis of the referential meaning and general meaning of the items detected strong semantic equivalence, while the pre-test of the synthesised version showed a high rate of un- derstanding and acceptance of the questions among elderly patients $?$.

The aim of this study was to assess the psychometric properties of the Brazilian version of the VES-13 in a sample of elderly cancer patients.

\section{Material and methods}

Assuming $\alpha=0.05$ (two-sided test), 80\% power and a prevalence of 0.50 , the estimated sample size needed for this analysis was 201 individuals. A sample of 272 cancer patients aged 60 years and over and receiving care at an ambulatory cancer centre in the city of Campo Grande, Mato Grosso State, Brazil, were interviewed between March and April 2012.

Trained interviewers conducted a questionnaire containing the Brazilian version of the VES13 and other similar questions designed to assess construct validity. The first 108 individuals were interviewed again by the same interviewer after a period of seven to 15 days to measure test-retest reliability.

The study was approved by the Ethics Research Committee of the Sergio Arouca National School of Public Health at the Oswaldo Cruz Foundation (ENSP/Fiocruz) and all participants signed an informed consent form.

The VES-13 is made up of 13 items covering age (one question), self-rated health (one question), physical capacity (six questions) and functional capacity (five questions) and takes an average of five minutes to complete. With regard to item 1 (age), one point is assigned to individuals aged between 75 and 84 years and three points to those aged 85 years and over. Item 2 (self-rated health) has five possible answers (poor, fair, good, very good, and excellent), and one point is assigned for the options poor or fair. Items 3 to 8 (physical capacity) refer to the degree of difficulty in performing six activities and has five possible answers (none, a little, some, a lot of difficulty, or unable to do). One point is given for the answers "a lot of difficulty" or "unable to do the activity", with a maximum limit of two points. Items 9 to 13 (functional capacity) asked about difficulties in performing five activities of daily living due to health. Possible answers are "yes", "no" and "don't do". No points are given for these answers. If the answer is affirmative the individual is asked if he/she needs help to perform the activity (possible answers yes or no). If the answer is "don't do", he/she is asked if this is due to his/her health (possible answers yes/no). An affirmative answer to these latter two questions is assigned four points. The total score ranges between zero and 10 points. 
The vulnerability cutpoint is a score greater than or equal to three 1 .

During the first stage of the cross-cultural adaptation of the VES-13 for use with the Brazilian population we analysed the conceptual equivalence of the questionnaire and carried out a pretest of the synthesised version. We found that the concept vulnerable elder had the same meaning in the culture of origin as in the Brazilian culture and that the items which made up the instrument presented similarities in both cultures. The analysis of general and differential meanings showed strong semantic equivalence and pre-test results displayed a good level of understanding and acceptance among the target population 7 .

Test-retest reliability was measured using the Spearman correlation coefficient to analyse the correlation between age and self-rated health scores, between the scores for items 3 to 8 and items 9 to 13, and between the totalVES-13 scores. Intraclass correlation coefficients with their respective $95 \%$ confidence intervals (95\%CI) were calculated and the response options for items 1 to 13 were then dichotomized in accordance with the scoring criteria established for these items. The test-retest reliability of the answers to the questions of each item given by the respondents at the two points in time was also assessed using the simple percent agreement and Cohen's kappa coefficient. The kappa coefficient is generally thought to be a more robust measure than the simple percent agreement since it takes into account the agreement occurring by chance. We used the Landis \& Koch classification 8 to evaluate degree of agreement as follows: absent $(<$ $0.10)$, weak $(0.10-0.20)$, fair $(0.21-0.40)$, moderate (0.41-0.60), substantial (0.61-0.80), or nearly perfect agreement (0.81-1.00).

Principal component analysis was undertaken to evaluate construct validity and explore the dimensions of the tool using Pearson's correlation coefficients. It is important to note that this may lead to an underestimation of the magnitude of correlation coefficients and the possibility that some items end up in the wrong components 9 . The adequacy of the correlation matrix was measured using the Bartlett statistical test and the Kaiser-Meyer-Olkin (KMO) measure. Varimax rotation was used to identify the factors which best represented the items contained in the tool. The appropriate number of factors was determined based on the proportion of overall variance explained by each variable.

Construct validity was also measured by testing convergent and discriminant validity using indicators similar to the items contained in the VES-13 taken from tools routinely used to assess elderly patients in health care settings. For the analysis of convergent validity, we considered the strength and direction of the relationship of each item with its alternative indicator, while for discriminant validity, we examined the relationship between VES-13 items and corresponding alternative indicators and the relationship between the functions (physical capacity and functional capacity) and corresponding alternative measurements.

\section{Results}

The mean and median age of the participants was $71.6( \pm 0.4)$ and 71 years, respectively. The youngest participant was aged 60 years, while the oldest member of the sample was aged 97 . The predominant age group was 60 to 74 years ( $\mathrm{n}=176$, or $67.4 \%$ of the sample). The majority of the sample were male $(n=157$, or $61.6 \%$ of the sample). The prevalence of vulnerability based on a cutpoint score of greater than or equal to three was $50.4 \%(n=137)$. No statistically significant differences were found in relation to gender, age group and vulnerability condition between the overall sample and sub-sample of older people re-interviewed to measure testretest reliability.

The Spearman correlation coefficient $(\rho)$ for total VES-13 scores in the test-retest was 0.67 (p $<0.001)$. The scores for the age item $(\rho=0.98$; $\mathrm{p}<0.001)$, self-rated health item $(\rho=0.52 ; \mathrm{p}<$ 0.0001 ), physical capacity items 3 to 8 ( $\rho=0.66$; $\mathrm{p}<0.001$ ), and functional capacity items 9 to 13 ( $\rho=0.48 ; p<0.001$ ) showed a strong to moderate statistically significant correlation, demonstrating reasonable test-retest reliability.

Average scores for the VES-13 varied between 0.42 (age) and 1.37 (functional capacity) in the test, and between 0.41 (age) and 1.33 (functional capacity) in the retest. Estimated average scores and intraclass correlation coefficients are shown in Table 1. All the intraclass correlation coefficients were greater than 0.60 .

Simple agreement between the answers given to the VES-13 questions in the two interviews ranged between 0.76 and 0.97 . The Landis \& Koch classification based on the kappa coefficients 8 showed the following degrees of agreement: nearly perfect agreement (one item), substantial agreement (three items), moderate (four items), and fair agreement (four items). These results are shown in Table 2.

The results of the Bartlett's sphericity test ( $p<0.001$ ) and a KMO index of 0.91 confirmed sample adequacy for principal component analysis. Three factors were retained which explained $72.6 \%$ of overall sample variance. 
Table 1

Average scores for the items, categories and overall Vulnerable Elders Survey-13 (VES-13) in the test-retest interviews and respective intraclass correlation coefficients.

\begin{tabular}{lccc}
\hline Items/categories & $\begin{array}{c}\text { Test } \\
\text { Average score (SD) }\end{array}$ & $\begin{array}{c}\text { Retest } \\
\text { Average score (SD) }\end{array}$ & $\begin{array}{c}\text { Intraclass correlation } \\
\text { coefficients (95\%Cl) }\end{array}$ \\
\hline Age (item 1) & $0.42(0.68)$ & $0.41(0.68)$ & $0.995(0.993-0.997)$ \\
Self-related health (item 2) & $0.44(0.50)$ & $0.50(0.50)$ & $0.689(0.545-0.787)$ \\
Physical capacity (items 3 to 8) & $0.94(0.89)$ & $0.90(0.88)$ & $0.779(0.706-0.863)$ \\
Functional capacity (items 9 to 13) & $1.37(0.90)$ & $1.33(0.90)$ & $0.651(0.490-0.762)$ \\
VES-13 (items 1 to 13) & $3.17(2.76)$ & $3.15(2.81)$ & $0.786(0.687-0.854)$ \\
\hline
\end{tabular}

95\% Cl: $95 \%$ confidence interval.

Simple agreement and chance corrected agreement (kappa coefficient) in the test-retest interviews by Vulnerable Elders Survey-13 (VES-13) item.

\begin{tabular}{|c|c|c|}
\hline VES-13 items & $\begin{array}{c}\text { Simple } \\
\text { agreement }\end{array}$ & Kappa \\
\hline 1. Age: & 0.97 & 0.94 \\
\hline 2. In general, compared to other people your age, would you say that your health is: & 0.76 & 0.52 \\
\hline 3. How much difficulty, on average, do you have with stooping, crouching or kneeling? & 0.84 & 0.62 \\
\hline 4. How much difficulty, on average, do you have with lifting or carrying objects as heavy as 10 pounds? & 0.81 & 0.51 \\
\hline 5. How much difficulty, on average, do you have with reaching or extending arms above shoulder level? & 0.92 & 0.56 \\
\hline 6. How much difficulty, on average, do you have with writing, or handling and grasping small objects? & 0.95 & 0.59 \\
\hline 7. How much difficulty, on average do you have with walking a quarter of a mile? & 0.85 & 0.60 \\
\hline 8. How much difficulty, on average, do you have with heavy housework such as scrubbing floors or washing windows? & 0.83 & 0.66 \\
\hline $\begin{array}{l}\text { 9. Because of your health or physical condition, do you have any difficulty shopping for personal items (like toilet } \\
\text { items or medicines)? }\end{array}$ & 0.78 & 0.43 \\
\hline $\begin{array}{l}\text { 10. Because of your health or physical condition, do you have any difficulty managing money (like keeping track of } \\
\text { expenses or paying bills)? }\end{array}$ & 0.80 & 0.41 \\
\hline 11. Because of your health or a physical condition, do you have any difficulty walking across the room? & 0.93 & 0.43 \\
\hline $\begin{array}{l}\text { 12. Because of your health or a physical condition, do you have any difficulty doing light housework (like washing } \\
\text { dishes, straightening up, or light cleaning)? }\end{array}$ & 0.90 & 0.62 \\
\hline 13. Because of your health or a physical condition, do you have any difficulty bathing or showering? & 0.94 & 0.33 \\
\hline
\end{tabular}

Table 3 presents the results of the analysis after the Varimax rotation. The first component included five functional capacity variables related to activities of daily living, each with positive loads ( $\geq 0.943$ ). In the second component, five of the six physical capacity items presented high positive loads $(\geq 0.667)$ and the self-rated item presented a moderate negative load. With respect to the third component, age was the only variable to present a high positive load. Low loads were observed for three of the physical capacity variables, two of which were negative (reaching or extending arms above shoulder lev$\mathrm{el}$, and writing, or handling and grasping small objects) and one positive (walking a quarter of mile).

Table 4 shows that the VES-13 has good convergent validity. As a whole, there was a strong and statistically significant correlation between the VES-13 items and alternative indicators. Only two items (managing money and doing light housework) presented values below 0.20 and were also statistically significant. The correlations between the scores of the physical capacity and functional capacity items of the VES-13 and their respective alternative indicators demonstrate convergent validity of the Brazilian version of the tool (Table 5). 
Principal components and factor loading after Varimax rotation.

\begin{tabular}{|c|c|c|c|}
\hline \multirow[t]{2}{*}{ VES-13 items } & \multicolumn{3}{|c|}{ Components } \\
\hline & 1 & 2 & 3 \\
\hline Because of your health or a physical condition, do you have any difficulty walking across the room? & 0.954 & 0.262 & \\
\hline Because of your health or a physical condition, do you have any difficulty bathing or showering? & 0.954 & 0.262 & \\
\hline $\begin{array}{l}\text { Because of your health or physical condition, do you have any difficulty managing money (like keeping track } \\
\text { of expenses or paying bills)? }\end{array}$ & 0.953 & 0.261 & \\
\hline $\begin{array}{l}\text { Because of your health or a physical condition, do you have any difficulty doing light housework (like washing } \\
\text { dishes, straightening up, or light cleaning)? }\end{array}$ & 0.945 & 0.275 & \\
\hline $\begin{array}{l}\text { Because of your health or physical condition, do you have any difficulty shopping for personal items (like toilet } \\
\text { items or medicines)? }\end{array}$ & 0.943 & 0.274 & \\
\hline How much difficulty, on average, do you have with stooping, crouching or kneeling? & 0.169 & 0.768 & \\
\hline How much difficulty, on average, do you have with lifting or carrying objects as heavy as 10 pounds? & 0.243 & 0.747 & \\
\hline $\begin{array}{l}\text { How much difficulty, on average, do you have with heavy housework such as scrubbing floors or washing } \\
\text { windows? }\end{array}$ & 0.335 & 0.744 & \\
\hline How much difficulty, on average, do you have with reaching or extending arms above shoulder level? & 0.198 & 0.682 & -0.384 \\
\hline How much difficulty, on average do you have with walking a quarter of a mile? & 0.305 & 0.667 & 0.225 \\
\hline In general, compared to other people your age, would you say that your health is: & -0.154 & -0.504 & \\
\hline How much difficulty, on average, do you have with writing, or handling and grasping small objects? & 0.121 & 0.499 & -0.336 \\
\hline Age: & & 0.148 & 0.851 \\
\hline
\end{tabular}

VES-13: Vulnerable Elders Survey-13.

Note: variables that make up each factor are in bold.

The analysis of the correlations between the alternative indicators and VES-13 items also indicate reasonable discriminant validity. The analysis of alternative indicators for physical capacity showed a strong correlation between the alternative indicators picking up an object from the floor and performing moderate physical activities and the bathing item (functional capacity) of the VES13. The alternative indicator for the functional capacity item "Do you have problems in your daily life due to difficulty in walking?" showed a strong correlation with the VES-13 functional capacity items "difficulty walking 400 meters" and "difficulty performing heavy housework". The alternative indicator "Can you tidy your house?" presented a strong correlation with the VES-13 physical capacity item "difficulty in performing heavy housework” (Table 5).

\section{Discussion}

This study is a continuation of the cross-cultural adaptation of the VES-13 for use with the Brazilian population. Adopting a universalist approach 10 it tests the psychometric properties of the Brazilian version with a sample of cancer patients aged 60 years and over.
Mohile et al. 2 assessed the test-retest reliability of the VES-13 by conducting two interviews 30 days apart with a convenience sample of 50 individuals aged 70 years and over and using Pearson correlation coefficient to compare the scores of the first and second interviews. The value of $r$ was 0.92 , which is higher than the value observed by the present study using the Spearman correlation coefficient. However, a comparison of specific items showed that values were practically the same in both studies, with the exception of the functional capacity items, whose values were higher in the study conducted by Mohile et al. ${ }^{2}$. However, these authors did not calculate intraclass correlation coefficients, simple percent agreement or kappa coefficients, and therefore a direct comparison between the studies' findings is not possible.

The analysis of intraclass correlation coefficients and kappa coefficients demonstrated the relative stability of the VES-13 items and categories. In test-retest studies, retested individuals may remember answers given in the first interview, which means that coefficients may be overestimated. Furthermore, real changes in the health of individuals may occur during the interval between the two interviews. An interval of 7 to 15 days was therefore chosen to minimize these problems. 
Table 4

Correlations between Vulnerable Elders Survey-13 (VES-13) items and alternative indicators.

\begin{tabular}{|c|c|c|c|}
\hline VES-13 item & Alternative indicator & $r$ & $\mathrm{p}$-value \\
\hline Age: & What day, month and year were you born? & 0.885 & $<0.001$ \\
\hline $\begin{array}{l}\text { In general, compared to other people your age, would you say that } \\
\text { your health is: }\end{array}$ & How would you describe your health? & 0.606 & $<0.001$ \\
\hline \multicolumn{4}{|l|}{ Physical capacity } \\
\hline $\begin{array}{l}\text { How much difficulty, on average, do you have with stooping, } \\
\text { crouching or kneeling? }\end{array}$ & $\begin{array}{l}\text { Are you able to pick up an object that has fallen on } \\
\text { the floor? }\end{array}$ & 0.278 & $<0.001$ \\
\hline $\begin{array}{l}\text { How much difficulty, on average, with lifting or carrying objects as } \\
\text { heavy as } 10 \text { pounds? }\end{array}$ & $\begin{array}{l}\text { How many days last week did you perform } \\
\text { moderate physical activities for at least } 10 \text { minutes } \\
\text { continuously? }\end{array}$ & 0.222 & $<0.001$ \\
\hline $\begin{array}{l}\text { How much difficulty, on average, do you have with reaching or } \\
\text { extending arms above shoulder level? }\end{array}$ & $\begin{array}{l}\text { Do you have any difficulty reaching objects in a high } \\
\text { place, such as a glass on a shelf? }\end{array}$ & 0.452 & $<0.001$ \\
\hline $\begin{array}{l}\text { How much difficulty, on average, do you have with writing, or } \\
\text { handling and grasping small objects? }\end{array}$ & $\begin{array}{l}\text { Do you have any difficulty picking up a coin from a } \\
\text { table? }\end{array}$ & 0.382 & $<0.001$ \\
\hline $\begin{array}{l}\text { How much difficulty, on average, do you have with walking a quarter } \\
\text { of a mile? }\end{array}$ & $\begin{array}{l}\text { Do you have any difficulty going up one flight of } \\
\text { stairs? }\end{array}$ & 0.538 & $<0.001$ \\
\hline $\begin{array}{l}\text { How much difficulty, on average, do you have with heavy housework, } \\
\text { such as scrubbing floors or washing windows? }\end{array}$ & $\begin{array}{l}\text { How many days last week did you perform } \\
\text { vigorous physical activities for at least } 10 \text { minutes } \\
\text { continuously? }\end{array}$ & 0.276 & $<0.001$ \\
\hline \multicolumn{4}{|l|}{ Functional capacity } \\
\hline $\begin{array}{l}\text { Because of your health or a physical condition, do you have any } \\
\text { difficulty shopping for personal items (like toilet items or medicines)? }\end{array}$ & Are you able to do shopping? & 0.287 & $<0.001$ \\
\hline $\begin{array}{l}\text { Because of your health or a physical condition, do you have any } \\
\text { difficulty managing money (like keeping track of expenses or } \\
\text { paying bills)? }\end{array}$ & Are you able to look after your money? & 0.146 & 0.008 \\
\hline $\begin{array}{l}\text { Because of your health or a physical condition, do you have any } \\
\text { difficulty walking across the room? }\end{array}$ & $\begin{array}{l}\text { Do you have any problems in your daily life due to } \\
\text { difficulty in walking? }\end{array}$ & 0.513 & $<0.001$ \\
\hline $\begin{array}{l}\text { Because of your health or a physical condition, do you have any } \\
\text { difficulty doing light housework (like washing dishes, straightening } \\
\text { up, or light cleaning)? }\end{array}$ & Are you able to tidy your house? & 0.140 & 0.011 \\
\hline $\begin{array}{l}\text { Because of your health or a physical condition, do you have any } \\
\text { difficulty bathing or showering? }\end{array}$ & Do you need help to take a bath? & 0.971 & $<0.001$ \\
\hline
\end{tabular}

The VES-13 is a tool for identifying vulnerable older people that considers age, self-rated health, physical capacity and functional capacity. Principal component analysis, used to assess construct validity, grouped functional capacity items and physical capacity items into separate components. Although some of these items loaded onto the other component, these loadings were comparatively low, in line with the original proposal of the tool regarding functional capacity and physical capacity. A study conducted in Japan showed that a loss of function in the elderly was preceded by a reduction in mobility 11 . Results related to self-rated health were as expected, showing negative loadings on the physical capacity and functional capacity components, grouped into the former component. The sepa- ration of age into a third component highlights the importance of giving greater emphasis to the contribution of this variable in the instrument, as suggested by a study conducted in Ireland 12 .

On the whole, the Brazilian version of the VES-13 presented good results in relation to convergent validity as shown by the positive and statistically significant correlations between the tool's items and alternative indicators. However, the correlation coefficient values of two functional capacity items ("because of your health or a physical condition, do you have any difficulty managing money" and "because of your health or a physical condition, do you have any difficulty doing light housework") were low, albeit statistically significant. A possible explanation for this weaker correlation may be the fact that 
Table 5

Correlations between Vulnerable Elders Survey-13 (VES-13) items and alternative indicators

\begin{tabular}{|c|c|c|c|c|c|c|c|}
\hline \multirow{2}{*}{$\begin{array}{l}\text { Alternative * } \\
\text { indicators }\end{array}$} & \multirow{2}{*}{$\begin{array}{c}\text { Physical capacity } \\
\qquad(p)\end{array}$} & \multicolumn{6}{|c|}{ VES-13 items ** } \\
\hline & & 1 & 2 & 3 & 4 & 5 & \\
\hline A & $0.200(<0.001)$ & $0.075(0.108)$ & $0.041(0.157)$ & 0.225 (0.079) & $0.018(0.381)$ & $0.306(0.050)$ & \\
\hline B & $0.213(<0.001)$ & $0.095(0.058)$ & $0.048(0.218)$ & $0.015(0.464)$ & $0.104(0.043)$ & $0.284(<0.001)$ & \\
\hline C & $0.471(<0.001)$ & $0.122(0.022)$ & $0.088(0.075)$ & $0.144(0.184)$ & $0.058(0.171)$ & $0.059(0.378)$ & \\
\hline D & $0.179(0.002)$ & $0.012(0421)$ & $0.068(0.131)$ & $0.083(0.302)$ & $0.056(0.177)$ & $0.059(0.378)$ & \\
\hline$E$ & $0.550(<0.001)$ & $0.091(0.067)$ & $0.046(0.225)$ & $0.193(0.114)$ & $0.046(0.225)$ & $0.272(0.073)$ & \\
\hline$F$ & $0.175(0.002)$ & $0.026(0.335)$ & $0.036(0.277)$ & $0.123(0.022)$ & $0.033(0.294)$ & $0.096(0.056)$ & \\
\hline $\begin{array}{l}\text { Alternative * } \\
\text { indicators }\end{array}$ & $\begin{array}{c}\text { Functional } \\
\text { capacity } \\
r(p)\end{array}$ & 6 & 7 & 8 & 9 & 10 & 11 \\
\hline G & $0.677(<0.001)$ & $0.392(<0.001)$ & $0.467(<0.001)$ & $0.247(<0.001)$ & $0.245(<0.001)$ & $0.473(<0.001)$ & $0.512(0.001)$ \\
\hline $\mathrm{H}$ & $0.616(<0.001)$ & $0.297(<0.001)$ & $0.360(<0.001)$ & $0.227(<0.001)$ & $0.268(<0.001)$ & $0.345(<0.001)$ & $0.424(<0.001)$ \\
\hline I & $0.533(<0.001)$ & $0.456(<0.001)$ & $0.421(<0.001)$ & $0.364(<0.001)$ & $0.272(<0.001)$ & $0.674(<0.001)$ & $0.534(<0.001)$ \\
\hline$J$ & $0.534(<0.001)$ & $0.419(<0.001)$ & $0.494(<0.001)$ & $0.334(<0.001)$ & $0.300(<0.001)$ & $0.486(<0.001)$ & $0.688(<0.001)$ \\
\hline K & $0.295(<0.001)$ & $0.162(0.004)$ & $0.227(<0.001)$ & $0.118(0.026)$ & $0.165(0.003)$ & $0.159(0.004)$ & $0.180(0.001)$ \\
\hline
\end{tabular}

* A. Are you able to pick up an object that has fallen on the floor?; B. How many days last week did you perform moderate physical activities for at least 10 minutes continuously?; C. Do you have any difficulty reaching objects in a high place, such as a glass on a shelf?; D. Do you have any difficulty picking up a coin from a table?; E. Do you have any difficulty going up one flight of stairs?; F. How many days last week did you perform vigorous physical activities for at least 10 minutes continuously?; G. Are you able to do shopping?; $\mathrm{H}$. Are you able to look after your money?; I. Do you have any problems in your daily life due to difficulty in walking?; J. Are you able to tidy your house?; K. Do you need help to take a bath?;

** 1. Because of your health or a physical condition, do you have any difficulty shopping for personal items?; 2 . Because of your health or a physical condition, do you have any difficulty managing money?; 3. Because of your health or a physical condition, do you have any difficulty walking across the room?; 4. Because of your health or a physical condition, do you have any difficulty doing light housework?; 5 . Because of your health or a physical condition, do you have any difficulty bathing or showering?; 6. How much difficulty, on average, do you have with stooping, crouching or kneeling?; 7. How much difficulty, on average, do you have with lifting, or carrying objects as heavy as 10 pounds?; 8 . How much difficulty, on average, do you have with reaching or extending arms above shoulder level?; 9. How much difficulty, on average, do you have with writing, or handling and grasping small objects?; 10. How much difficulty, on average, do you have with walking a quarter of a mile?; 11. How much difficulty, on average, do you have with heavy housework, such as scrubbing floors or washing windows?

the alternative indicators are related to only a part of the respective construct and are therefore not fully equivalent, which could have also resulted in incorrect responses from the interviewees. These two questions are more detailed in the VES-13 and even use examples. However, these indicators were maintained since more comprehensive alternatives were not available.

With respect to discriminant validity, physical capacity and functional capacity items were grouped into separate components. Furthermore, the correlation between these VES-13 items and the alternative indicators was generally stronger and more statistically significant, with only two physical capacity items and one functional capacity item showing a weaker correlation with the alternative indicators. This may be due to the complex interrelations between these two categories. Walking and mobility in general are related to activities of daily living which are evaluated within the functional capacity category and therefore physical difficulties may overlap into functional difficulties 11 .

It was not possible to compare our findings since we were unable to find similar studies that analysed the validity of VES-13 in the Brazilian context.

Although we sought to select adequate alternative indicators from different assessment tools of older people used in Brazil, it is possible that certain indicators were not sufficiently similar to its respective item. However, based on the results obtained, we believe that the Brazilian version of the VES-13 demonstrates good convergent and discriminant validity.

Studies of the psychometric properties of the VES-13 are limited to the analysis of predictive validity for adverse health outcomes or criterion validity in relation to an arbitrary gold standard (CGA) $1,2,5,13,14,15$. It is therefore impor- 
tant to advance the assessment of the Brazilian version of this tool by investigating predictive validity with respect to outcomes such as loss of function, toxicity and death among elderly cancer patients.

Another limitation is the fact that the individuals assessed by this study were part of a convenience sample of patients receiving care at an ambulatory cancer centre in Campo Grande. However, the main objective of adapting the VES13 was to use the tool with this target group.

The VES-13 is a short tool originally based on a self-reporting questionnaire 1 . However, considering the context of cancer care and the low level of schooling among the target group, it was decided that the questionnaire would be filled in by an interviewer 7. Despite this, the Brazilian version of the VES-13 retains its original characteristics as an easily applicable and low-cost tool that can be used in different levels of care 2,5,13.

The analyses conducted by this study indicate that the psychometric properties of the cross-cultural adaptation of the VES-13 are consistent and adequate for use with the Brazilian population. However, we emphasise the need for further research to assess predictive validity and criterion validity in comparison with a consensus-based gold standard.

\section{Resumen}

Este estudio tiene como objetivo evaluar las propiedades psicométricas de la versión brasileña del Vulnerable Elders Survey-13 (VES-13). Se realizaron entrevistas con individuos de 60 o más años, tratados en un ambulatorio de un hospital oncológico. La fiabilidad test-retest fue evaluada con coeficientes de correlación de Spearman, coeficientes de correlación intraclase y kappa. El análisis exploratorio para la evaluación del constructo por análisis de componentes principales se realizó con rotación varimax. La validez del constructo se examinó a través de la validez convergente y divergente. Los coeficientes de correlación de Spearman entre las puntuaciones de la prueba y el retest fueron $0,98(p<0,001)$. Todos los coeficientes de correlación intraclase presentaron valores superiores a 0,60 y los coeficientes Kappa oscilaron entre 0,33 y 0,94. Tres factores explicaron un 72,6\% de la varianza total. El VES-13 presentó buena validez convergente y razón divergente. La versión brasileña del VES-13 presenta propiedades psicométricas consistentes.

Anciano; Psicometría; Comunidades Vulnerables

\section{Contributors}

L. L. Luz participated in all stages of this study including study design, data collection, statistical analysis, data quality control, and the drafting and revision of this manuscript. L. M. Santiago and I. E. Mattos collaborated with data collection, statistical analysis, and the drafting and revision of this manuscript. J. F. S. Silva contributed towards data collection, data quality control, and the drafting and revision of this manuscript.

\section{Acknowledgments}

This study received financial support from Fiocruz/ CNPq's Technological Development in Public Health Programme (PDTSP) and the Fundação Carlos Chagas' Unified Health System Research Programme (PPSUS). 


\section{References}

1. Saliba D, Elliott M, Rubenstein LZ, Solomon DH Young RT, Kamberg CJ, et al. The Vulnerable Elders Survey: a tool for identifying vulnerable older people in the community. J Am Geriatr Soc 2001; 49:1691-9.

2. Mohile SG, Bylow K, Dale W, Dignam J, Petrylac DP, Stadler WM, et al. A pilot study of the Vulnerable Elders Survey-13 compared with the Comprehensive Geriatric Assessment for identifying disability in older patients with prostate cancer who receive androgen ablation. Cancer 2007; 109:802-10.

3. Rodin MB, Mohile SG. A practical approach to geriatric assessment in oncology. J Clin Oncol 2007; 25:1936-44.

4. Kellen E, Bulens P, Deckx L, Schouten H, Van Dijk $\mathrm{M}$, Verdonck I, et al. Identifying an accurate prescreening tool in geriatric oncology. Crit Rev Oncol Hematol 2010; 75:243-8.

5. Luciani A, Ascione G, Bertuzzi C, Marussi D, Codecà $C$, Di Maria G, et al. Detecting disabilities in older patients with cancer: comparison between Comprehensive Geriatric Assessment and Vulnerable Elders Survey-13. J Clin Oncol 2010; 28: 2046-50.

6. Molina-Garrido MJ, Guillén-Ponce C. Comparison of two frailty screening tools in older women with early breast cancer. Crit Rev Oncol Hematol 2011; 79:51-64.

7. Luz LL, Santiago LM, Silva JFS, Mattos IE. Primeira etapa da adaptação transcultural do instrumento The Vulnerable Elders Survey (VES-13) para o Português. Cad Saúde Pública 2013; 29:621-8.

8. Landis JR, Koch GG. The measurement of observer agreement for categorical data. Biometrics 1977; 33:159-74.

9. Costello AB, Osborne JW. Best practices in exploratory factor analysis: four recommendations for getting the most from your analysis. Practical Assessment, Research \& Evaluation 2005; 10:1-9.
10. Herdman M, Fox-Rushby J, Badia X. A model of equivalence in the cultural adaptation of HRQol instruments: the universalist approach. Qual Life Res 1998; 7:323-35.

11. Kono K, Katsumata Y, Arai A, Tamashiro H. Functional status and active life expectancy among senior citizens in a small town in Japan. Arch Gerontol Geriatr 2004; 38:153-66.

12. McGee HM, O'Hanlon A, Barker M, Hickey A, Montgomery A, Conroy R, et al. Vulnerable older people in the community: relationship between the Vulnerable Elders Survey and health service use. J Am Geriatr Soc 2008; 56:8-15.

13. Min LC, Elliott MN, Wenger NS, Saliba D. Higher vulnerable elders survey scores predict death and functional decline in vulnerable older people. J Am Geriatr Soc 2006; 54:507-11.

14. Min L, Yoon W, Mariano J, Wenger NS, Elliott MN, Kamberg C, et al. The Vulnerable Elders-13 Survey predicts 5-year functional decline and mortality outcomes in older ambulatory care patients. J Am Geriatr Soc 2009; 57:2070-6.

15. Min L, Ubhayakar N, Saliba D, Kelley-Quon L, Morley E, Hiatt J, et al. The Vulnerable Elders Survey-13 predicts hospital complications and mortality in older adults with traumatic injury: a pilot study. J Am Geriatr Soc 2011; 59:1470-6.

Submitted on $27 / \operatorname{Jan} / 2014$

Final version resubmitted on 21/Oct/2014

Approved on 06/Nov/2014 